\title{
The Quantitative Measurement of ST-Segment Deviation and Pathological Q Wave for Predicting in-Hospital Mortality in Patient with ST-Elevation Myocardial Infarction
}

\author{
Muhammad Surya Tiyantara1, Yustye 2 , Dioen Herdianto 3 , Swandari Paramita ${ }^{4}$
}

\begin{abstract}
Background: The appearance of ST-segment elevation (STE) and pathological $\mathrm{Q}$ wave were signs of worse myocardial damage and function, the quantitative measurement of the waves have a potential prognosis role. This study assesses the performance of the quantitative measurement of the waves in predicting in-hospital mortality and compares it with the Global Registry of Acute Coronary Events (GRACE) score as the standard recommended risk score.

Methods: This was a cross-sectional study included patients with ST-elevation myocardial infarction (STEMI) that hospitalized in Abdul Wahab Sjahranie General Hospital Samarinda during January to December 2016. Standard I2-lead electrocardiograms (ECG) were assessed at patient admission as well as other data for GRACE score. The subjects were grouped into non-survivor and survivor group based on hospitalization survival state, and six quantitative ECG characteristics performance will be assessed. The performances were assessed using receiver operating characteristics (ROC) curve and area under the curve (AUC).

Results: There were 57 subjects consisting of 9 non-survivor subjects. The AUC of the four ECG characteristics highest STE amplitude, deepest $Q$ amplitude, total $Q$ amplitude, and total STE amplitude did not significantly different with GRACE score ( $p>0.05)$. Highest STE amplitude has the best performance than the other ECG characteristics (AUC $=0.8 \mathrm{I}, 95 \% \mathrm{Cl}: 0.65$ to 0.97 ), and cut off point $4.5 \mathrm{~mm}$ provides $56 \%$ sensitivity and $94 \%$ specificity.

Conclusion: The quantitative measurement of ST-segment deviation and pathological $Q$ wave have the prognosis role for predicting in-hospital mortality.
\end{abstract}

(Indonesian J Cardiol. 2019;40:275-28I)

Keywords: pathological Q wave, ST-segment deviation, ST-elevation myocardial infarction, prognosis

I Faculty of Medicine, Mulawarman University, Samarinda, Indonesia

${ }^{2}$ General Practitioner, Abdul Wahab Sjahranie Hospital, Samarinda, Indonesia

3 department of Cardiology and Vascular Medicine, Abdul Wahab Sjahranie Hospital, Samarinda, Indonesia

${ }^{4}$ Laboratory of Public Health, Faculty of Medicine, Mulawarman

University, Samarinda, Indonesia

\section{Correspondence:}

Muhammad Surya Tiyantara, MD

Faculty of Medicine Mulawarman University, Samarinda,

Indonesia

E-mail: suryatiyantara@gmail.com

\section{Introduction}

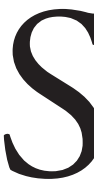

T-elevation myocardial infarction (STEMI) is one of the acute coronary syndrome (ACS) spectrum identified by the presence of the myocardial ischemia symptom, and persistent ST-segment elevation (STE). ${ }^{1}$ The mortality of this ACS type is higher than the other type. ${ }^{2,3}$ Most of this type will be evolved into $\mathrm{Q}$ wave myocardial infarction by the presence of pathological Q wave. ${ }^{2,4}$

Ischemic risk assessment is recommended for a patient with acute myocardial infarction (AMI), not only 
for prognosis assessment but also help to determine the treatment strategy. 1,5 Global Registry of Acute Coronary Events (GRACE) score is one of risk stratification score that can estimate mortality in hospital, at 6 months, 1 year, and 3 years, European Society of Cardiology (ESC) recommends the use of this risk score for the patient with AMI, include STEMI patient. ${ }^{1,5}$

The appearance of STE and pathological Q wave were signs of worse myocardial damage and function. On electrophysiological perspective, STE is a sign of the electrical shift of ST-segment because of abnormality of $\mathrm{K}+$ channel result from transmural myocardial ischemia, while the pathological Q waves are signs of the electrical window, an area that severely electrically impaired, ranging from hibernating, stunning, and necrosis of myocardium. ${ }^{6-9}$

Our hypotheses are the characteristics and magnitude of the STE and pathological Q wave have prognostic a role. In this study, we determine the quantitative measurement of STE and pathological Q wave and its performance in predicting the in-hospital mortality and compare it with GRACE score as the standard risk score for STEMI.

\section{Methods}

The subjects were STEMI patients who were treated in period January to December 2016 in the Abdul Wahab Sjahranie General Hospital in Samarinda, East Kalimantan. ESC criteria for STEMI were used to define the STEMI diagnosis. STEMI was defined by the presence of symptom consistent with myocardial ischemia (eg. persistent chest pain) and ECG sign that meets the STEMI criteria, ST-segment elevation (measured using J-point, and two consecutive PR interval as a baseline), at two or more contiguous leads with elevation $\geq 2.5 \mathrm{~mm}$ in men $<40$ years, $\geq 2.0 \mathrm{~mm}$ in men $>40$ years, or $\geq 1.5 \mathrm{~mm}$ in the woman in leads $\mathrm{V}_{2}-\mathrm{V}_{3}$ and/or $\geq 1 \mathrm{~mm}$ in other leads. Standard 12-lead ECG calibration $10 \mathrm{~mm} / \mathrm{mV}$ and $25 \mathrm{~mm} / \mathrm{s}$ were used in this study. Standard treatment such as thrombolytic, anticoagulant, antiplatelet, and other medications are used as indicated.

The subjects were grouped into a non-survivor and survivor group based on the survival state during hospitalization. The ECG characteristics and GRACE score are compared between the group, and the performance of these variables to predict mortality will also be analyzed. Exclusion criteria are subject with a history of AMI, poor quality ECG and/or with QRS confounders (e.g. left bundle branch block).

There are six ECG characteristics included as variables in this study. The definitions of the variables are shown in table 1. Pathological Q waves are defined as Q-wave with a duration of $\geq 40 \mathrm{~ms}$ and/or a depth $\geq 25 \%$ of the R-wave in the same lead, that present in two or more contiguous leads. The ECG characteristics were measured by a physician manually based on the ECG criteria. GRACE score is obtained by calculating the characteristics of the subject that include the age, heart rate, systolic blood pressure, creatinine level, Killip class, cardiac arrest at admission, ST-segment deviation, and cardiac enzymes. All of the ECG characteristics and data to determine the GRACE score are obtained from the medical record at the time of patient admission.

Kolmogorov-Smirnov test was used to asses the normality distribution of the data. Variables with continuous type were presented as mean and standard deviations for data that normally distributed, or median (25th percentile, 75 th percentile) for data that not normally distributed. Variables with categorical type were presented as an absolute number with a percentage. Independent T-test or Mann-Whitney test was used to compare the continuous variables that depend on the distribution of the data, while the Chi-Square test or Fisher exact test was used to compare noncontinuous variables. The performance of the diagnostic value of ECG characteristics and GRACE score to predict inhospital mortality were assessed using receiver operating characteristic (ROC) curve and area under the curve (AUC). Statistical significance is obtained when $\mathrm{P}<0.05$. All analyses were done using IBM SPSS statistics version 19, except for comparison (c-statistic) of the ROC curve and AUC (DeLong method) that using Medcalc statistical software version 18.6.

\section{Results}

A total of 57 subjects were included in this study. There were 9 non-survivor subjects during hospitalization, they had higher Killip class and troponin-T value on admission than survivor subjects. The characteristics of the subject are shown in table 2 . 
Indonesian Journal of Cardiology

\section{ST-segment deviation}

Table 3 shows the result of Mann-Whitney test of the ST-segment deviation characteristics. The maximum value of highest STE amplitude of the non-survivor and survivor group were $9 \mathrm{~mm}$ and $6 \mathrm{~mm}$ respectively, while maximum number involved lead with STE and maximum total STE amplitude in the non-survivor group were 8 leads and $28 \mathrm{~mm}$, and 6 leads and $27 \mathrm{~mm}$ in the survivor group.

\section{Pathological Q wave}

The non-survivor group had the maximum value of deepest $\mathrm{Q}$ amplitude and the maximum value of number involved lead $4 \mathrm{~mm}$ and 5 leads, respectively, as well as survivor group. The maximum value of the total $Q$ amplitude in the non-survivor group was $13 \mathrm{~mm}$, and $10 \mathrm{~mm}$ in the survivor group. The results of the MannWhitney test of the pathological Q wave characteristics are shown in table 3 .

\section{GRACE score}

The median of GRACE score in this study was 138 . The non-survivor group had higher GRACE score than the survivor group $(207(150,227)$ and $133(113,150)$, $\mathrm{p}=0.001)$ using the Mann-Whitney test. The highest and lowest GRACE score in the non-survivor group were 257 and 155, and in the survivor group 200 and 89 , respectively.

\section{ECG characteristics and GRACE score perfor- mance}

The performance of the ECG characteristics and GRACE score in predicting the in-hospital mortality are shown in figure 1. Highest STE amplitude had the best performance than the other ECG characteristics (AUC $=0.81,95 \%$ CI:0.65 to 0.97), cut off point of highest STE amplitude $3.5 \mathrm{~mm}$ had $78 \%$ sensitivity and $65 \%$ specificity, and cut off point $4.5 \mathrm{~mm}$ had $56 \%$ sensitivity and $94 \%$ specificity. Highest STE amplitude, deepest Q amplitude, total Q amplitude, and total STE amplitude were not significantly different with GRACE score in predicting in-hospital mortality using DeLong method for AUC and standard error comparison (table4).
Table 1. Operational definitions of the Electrocardiogram (ECG) characteristics

\begin{tabular}{|c|c|}
\hline & Definition \\
\hline Number lead with STE & $\begin{array}{l}\text { The number of lead in standard } \\
\text { 12-lead ECG that contains the ST- } \\
\text { segment elevation. }\end{array}$ \\
\hline Highest STE amplitude & $\begin{array}{l}\text { The highest/maximum deviation } \\
\text { of the ST-segment elevation in } \\
\text { standard 12-lead ECG. The degree } \\
\text { of elevation is measured at J-point } \\
\text { of the highest ST-elevation and } \\
\text { presented as mm. }\end{array}$ \\
\hline Total STE amplitude & $\begin{array}{l}\text { The sum of all ST-segment } \\
\text { elevation amplitude in all lead that } \\
\text { contains ST-segment elevation } \\
\text { in standard 12-lead ECG. The } \\
\text { degree of elevation is measured at } \\
\text { J-point in all lead that contains ST- } \\
\text { segment elevation and presented } \\
\text { as mm. }\end{array}$ \\
\hline Number lead with Q & $\begin{array}{l}\text { The number of lead in standard } \\
\text { 12-lead ECG that contains the } \\
\text { pathological Q wave. }\end{array}$ \\
\hline Deepest Q amplitude & $\begin{array}{l}\text { The deepest/maximum amplitude } \\
\text { of the Q wave in standard 12-lead } \\
\text { ECG. The degree of amplitude is } \\
\text { presented as } \mathrm{mm} \text {. }\end{array}$ \\
\hline Total Q amplitude & $\begin{array}{l}\text { The sum of all Q wave amplitude } \\
\text { in all lead that contains } \\
\text { pathological Q wave in standard } \\
\text { 12-lead ECG. The degree of } \\
\text { amplitude is presented as } \mathrm{mm} \text {. }\end{array}$ \\
\hline
\end{tabular}

STE=ST-segment elevation

\section{Discussion}

The ECG characteristics have the prognostic information in STEMI patients and help identification of group who will have benefit with more aggressive intervention. ${ }^{10,11}$ In this study we found that ECG characteristics had comparable performance to GRACE score. The performance of the four ECG characteristics highest STE amplitude, deepest Q amplitude, total Q amplitude, and total STE amplitude had similar performance with GRACE score in predicting the inhospital mortality. The highest STE amplitude had the best performance than the other ECG characteristics. Different from the previous studies, in this study, we focused on the quantitative measurement of the wave, that is using a numeric scale for the amplitude of the waves, and we compare the performance of the multiple 
ECG parameter (ST-deviation and pathological Q wave characteristics), also comparing with the standard ischemic risk score, GRACE score.

During the progression of the STEMI, there are changes in the characteristic of ECG, the high-grade ischemia (grade 3 from three classifications of the ischemia) has STE with distortion of the QRS terminal (no $S$ wave in leads with usual Rs configuration or $\mathrm{J}$ point/R wave ratio $\geq 0.5$ in leads with usual $\mathrm{qR}$ configuration) reflecting the higher STE the higher grade of ischemia. ${ }^{12}$ The terminal QRS distortion in high-grade ischemia reflects the prolongation of Purkinje fibers in the ischemic region and reflects the worse ischemia and prognosis. ${ }^{12}$

A study from De Luca et al. using residual STE after primary percutaneous coronary intervention (PCI) shows that cumulative ST-segment deviation was an independent predictor of 1-year mortality $(R R=1.31$, 95\% CI: 1.06 to 1.63 , $\mathrm{p}=0.014) .{ }^{13}$ Cumulative STE has better performance (AUC=0.733) than STE resolution (AUC=0.636) or ST-segment deviation resolution (AUC=0.660) in predicting 1-year mortality. ${ }^{13}$ In another study using ST-segment deviation in the ECG lead that contains maximum STE after thrombolysis, the performances were $\mathrm{AUC}=0.761$ for 90 minutes after thrombolysis, and $\mathrm{AUC}=0.755$ after 180 minutes after thrombolysis for predicting 30-day mortality, these performances were better than the performance of sum of STE resolution and STE resolution in only the one lead showing the maximal deviation. ${ }^{14}$

The maximum STE also has better performance than the sum of STE resolution for predicting 180-day mortality (AUC 0.680 vs 0.622 ). ${ }^{15}$ Our study using the ECG that immediately measured when the patient on admission, the maximum magnitude of the STE also shows the best performance than the sum/total STE amplitude, and with better performance than the previous studies, and comparable with GRACE score.

Maximum residual STE magnitude provides prognostic information about another adverse event such as heart failure and shock but still better predicting the 90-day mortality (AUC $=0.802$ vs $\mathrm{AUC}=0.832) .{ }^{16} \mathrm{~A}$ study shows that a higher magnitude of STE associated with more total occlusion, less collateral circulation, lower left ventricular ejection fraction (LVEF) and higher infarct size. ${ }^{17}$ These parameters are known as the predictor of prognosis in patient with AMI.
Table 2. Subject characteristics

\begin{tabular}{lcc}
\hline \multicolumn{1}{c}{ Characteristics } & $\begin{array}{c}\text { Non-survivor } \\
(\mathrm{n}=9)\end{array}$ & $\begin{array}{c}\text { Survivor } \\
(\mathrm{n}=48)\end{array}$ \\
\hline Age, years* & $57 \pm 9$ & $56 \pm 10$ \\
Men, $\mathrm{n}(\%)$ & $7(78)$ & $41(85)$ \\
History, $\mathrm{n}(\%)$ & & \\
$\quad$ Diabetes mellitus & $5(55)$ & $13(27)$ \\
$\quad$ Hypertension & $4(44)$ & $20(42)$ \\
Heart rate, bpm $\dagger$ & $102(71,117)$ & $80(66,89)$ \\
Systolic blood pressure, & $120(80,130)$ & $130(120,140)$ \\
mmHg $\dagger$ & & \\
Diastolic blood pressure, & $70(\mathrm{U}, 80)$ & $80(76,90)$ \\
mmHg $\dagger$ & & $22(20,26)$ \\
Respiration rate, bpm $\dagger$ & $26(24,30)$ & $1(1,1)$ \\
Killip class $\dagger$ & $3(1,4)$ & $35(28,45)$ \\
Ureum, mg/dl $\dagger$ & $38(31,42)$ & $1(0.8,1.4)$ \\
Creatinine, mg/dl $\dagger$ & $1.2(0.9,1.5)$ \\
Troponin- $\mathrm{T}$ on \\
admission, ng/L $\dagger$
\end{tabular}

Prognostic role of the appearance pathological Q wave was known since years ago, but quantitative measurement and its relation to the degree of adverse event and cardiac performance still challenging. The sum of pathological amplitude is correlated with infarct size and cardiac function in the animal model. ${ }^{18}$ The appearance of the wave also reflects the worst ventricular function in the human subject. ${ }^{19}$ Another study shows that state of hibernation, stunning and/or necrosis are the conditions that responsible in the formation of the wave. ${ }^{6-9}$ A study found that the width of the baseline Q-wave in STEMI has a prognostic role in predicting 90-day mortality, congestive heart failure, or cardiogenic shock, the prognosis was worsened as the width increased. ${ }^{11}$

Another study shows that subjects with pathological Q wave on presentation were more frequently male, had higher heart rates, more advanced Killip class and had a longer time from the onset of symptoms to PCI. Subject with pathological Q wave had higher 1-year allcause mortality than subjects without the wave (baseline Q waves: 4.9\%; no baseline Q waves: 2.8\%; hazard ratio $=1.78,95 \% \mathrm{CI}: 1.29$ to $2.45, \mathrm{p}<0.001) .{ }^{20}$ The presence of $\mathrm{Q}$ waves on baseline ECG was associated with higher 90 -day mortality in men (hazard ratio=1.7, 
Indonesian Journal of Cardiology

Table 3. Electrocardiogram characteristics between the nonsurvivor and survivor group

\begin{tabular}{lccc}
\hline & $\begin{array}{c}\text { Non-survivor } \\
(\mathrm{n}=9)\end{array}$ & $\begin{array}{c}\text { Survivor } \\
(\mathrm{n}=48)\end{array}$ & p-value \\
\hline $\begin{array}{l}\text { Number lead with } \\
\text { STE, lead }\end{array}$ & $3(3,5)$ & $4(3,4)$ & 0.925 \\
$\begin{array}{l}\text { Highest STE } \\
\text { amplitude, mm }\end{array}$ & $5(3,5)$ & $3(3,4)$ & 0.002 \\
$\begin{array}{l}\text { Total STE } \\
\text { amplitude, mm }\end{array}$ & $13(8,20)$ & $10(7,12)$ & 0.030 \\
$\begin{array}{l}\text { Number lead with } \\
\text { Q, lead }\end{array}$ & $3(1,3)$ & $2(0,3)$ & 0.044 \\
$\begin{array}{l}\text { Deepest Q } \\
\text { amplitude, mm }\end{array}$ & $4(1,4)$ & $2(0,2)$ & 0.003 \\
$\begin{array}{l}\text { Total Q amplitude, } \\
\text { mm }\end{array}$ & $9(3,10)$ & $4(0,6)$ & 0.005 \\
$\begin{array}{l}\text { STE=ST-segment elevation; all characteristics are presented as } \\
\text { median(25 }\end{array}$ & \\
$\begin{array}{l}\text { Mann-Whitney test } \\
\text { Mann }\end{array}$ & &
\end{tabular}

95\% CI:1.0 to 2.7 ) and women (hazard ratio $=2.3,95 \%$ CI:1.2 to 4.2), the pathological Q wave was a better marker of risk than symptom onset to PCI. ${ }^{21}$

GRACE score is a risk stratification score that has good performance for prognosis stratification for ACS patient, ESC recommends the use of this score for ACS include STEMI patients.1,5 A study from Myocardial Infarction National Audit Project (MINAP) database shows that the performances of GRACE score are $\mathrm{AUC}=0.80$ (95\% CI:0.80 to 0.81) for in-hospital mortality, and AUC=0.80 (95\% CI:0.79 to 0.80 ) for 6-month mortality. ${ }^{22}$ In relation to hospital death, one study shows the performance of the GRACE score was AUC $=0.87$ (95\% CI:0.75 to 0.99). ${ }^{23}$ GRACE score performance in another study was similar to our study with $\mathrm{AUC}=0.83$ (95\% CI:0.79 to 0.87), the endpoints of the study were cardiac death, AMI and unstable angina within 30 -day. ${ }^{24}$

GRACE score has several components to measure, include the ST-deviation. The score only has dichotomous value for the ST-deviation not the quantitative measurement of deviation. This study found that the degree of deviation has comparable performance. Highest STE amplitude has the best performance than the other ECG characteristics and comparable with GRACE score, with high specificity in cut off point $4.5 \mathrm{~mm}$ whom acceptable for "rule in" criteria for clinical practice.

\section{Limitations}

For the purpose of better generalization to the population, we use only "immediate ECG measurement on admission" and not restricting with symptom onset, delay of treatment may confound the prognosis of the patient, but the variability in the onset may be the one that responsible in the variability of ECG characteristics. Also, this study was single-center study and the subjects were relatively small, the variability of the center protocol may affect the patient prognosis.

\section{Conclusions}

In conclusion, quantitative ECG characteristics have comparable prognostic value with GRACE score and good performance as mortality predictor, especially highest STE amplitude. Quantitative measurement of the waves may add the performance of the novel risk stratification scoring. Future study will be needed to including the quantitative measurement of ECG to prognosis scoring system.

\section{Ethical Clearance}

Ethical clearance number for this research is: 154 KEPK-AWS/IX/2018

\section{Conflict of Interest}

None

\section{Publication Agreement}

The authors give permission to Indonesian Journal of Cardiology to publish if this article is accepted

\section{Funding}

This research did not receive any specific grant from funding agencies in the public, commercial, or not-forprofit sectors.

\section{List of Abbreviations}

ACS=acute coronary syndrome

$\mathrm{AMI}=$ acute myocardial infarction 
$\mathrm{AUC}=$ area under the curve

$\mathrm{CI}=$ confidence interval

ECG=electrocardiogram

ESC=European Society of Cardiology

GRACE $=$ Global Registry of Acute Coronary Events

$\mathrm{LVEF}=$ left ventricular ejection fraction

MINAP=Myocardial Infarction National Audit Project

$\mathrm{PCI}=$ percutaneous coronary intervention

$\mathrm{ROC}=$ receiver operating characteristic

STE=ST-segment elevation

STEMI=ST-elevation myocardial infarction

\section{References}

1. Ibanez B, James S, Agewall S, Antunes MJ, Bucciarelli-Ducci C, Bueno H, et al. 2017 ESC Guidelines for the management of acute myocardial infarction in patients presenting with ST-segment elevation. Eur Heart J. 2017; 00:1-66.

2. Mandelzweig L, Battler A, Boyko V, Bueno H, Danchin N, Filippatos G, et al. The second Euro Heart Survey on acute coronary syndromes: Characteristics, treatment, and outcome of patients with ACS in Europe and the Mediterranean Basin in 2004. Eur Heart J. 2006; 27(19):2285-93.

3. Terkelsen C, Lassen J, Nørgaard B, Gerdes J, Jensen T, Gøtzsche LH, et al. Mortality rates in patients with ST-elevation vs. non-ST-elevation acute myocardial infarction: observations from an unselected cohort. Eur Heart J. 2005; 26(1):18-26.

4. Anderson JL, Adams CD, Antman EM, Bridges CR, Califf RM, Casey DE, et al. 2012 ACCF/AHA Focused Update Incorporated Into the ACCF/ AHA 2007 Guidelines for the Management of Patients With Unstable Angina/Non-ST-Elevation Myocardial Infarction. Circulation. 2013; 127:663828.

5. Roffi M, Patrono C, Collet JP, Mueller C, Valgimigli M, Andreotti F, et al. 2015 ESC Guidelines for the management of acute coronary syndromes in patients presenting without persistent ST-segment elevation. Eur Heart J. 2016; 37:267-315.

6. Mirvis DM, Goldberger AL. Electrocardiography. In: Mann DL, Zipes DP, Libby P, Bonow RO, Braunwald E, editors. Braunwald's Heart Disease: A Textbook of Cardiovascular Medicine. 10th ed. Philadelphia: Elsevier; 2015. p. 114-54.
7. Luna BA, Batchvarov VN, Malik M. The morphology of the electrocardiogram. In: Camm AJ, Luscher TF, Serruys PW, editors. ESC Textbook of Cardiovascular Medicine. 1st ed. Oxford: Blackwell Publishing; 2006. p. 1-36.

8. Sztajzel J, Urban P. Early and late Q wave regression in the setting of acute myocardial infarction. Heart. 2000; 83(6):708-10.

9. Voon WC, Chen YW, Hsu CC, Lai WT, Sheu SH. $\mathrm{Q}$-wave regression after acute myocardial infarction assessed by Tl-201 myocardial perfusion SPECT. J Nucl Cardiol. 2004; 11(2):165-70.

10. Maleki ND, Afshar AE, Armstrong PW. Use of electrocardiogram indices of myocardial ischemia for risk stratification and decision making of reperfusion strategies. J Electrocardiol. 2014; 47(4):520-4.

11. Bao M, Zheng Y, Westerhout C, Fu Y, Wagner G, Chaitman B, et al. Prognostic implications of quantitative evaluation of baseline Q-wave width in ST-segment elevation myocardial infarction. J Electrocardiol. 2014; 47(4):465-71.

12. Birnbaum Y, Drew BJ. The electrocardiogram in ST elevation acute myocardial infarction: correlation with coronary anatomy and prognosis. Postgrad Med J. 2003; 79:490-504.

13. De Luca G, Maas AC, Suryapranata H, Ottervanger JP, Hoorntje JCA, Gosselink ATM, et al. Prognostic significance of residual cumulative ST-segment deviation after mechanical reperfusion in patients with ST-segment elevation myocardial infarction. Am Heart J. 2005; 150(6):1248-54

14. Schröder K, Wegscheider K, Zeymer U, Neuhaus K, Schröder R. Extent of ST-segment deviation in the single ECG lead of maximum deviation present 90 or 180 minutes after start of thrombolytic therapy best predicts outcome in acute myocardial infarction. Z Kardiol. 2001; 90(8):557-67.

15. Schröder K, Wegscheider K, Zeymer U, Tebbe U, Schröde R. Extent of ST-segment deviation in a single electrocardiogram lead $90 \mathrm{~min}$ after thrombolysis as a predictor of medium-term mortality in acute myocardial infarction. Lancet. 2001; 358(9292):1479-86.

16. Buller C, Fu Y, Mahaffey K, Todaro T, Adams P, Westerhout C, et al. ST-segment recovery and outcome after primary percutaneous coronary 
intervention for ST-elevation myocardial infarction: insights from the Assessment of Pexelizumab in Acute Myocardial Infarction (APEX-AMI) trial. Circulation. 2008; 118(13):1335-46.

17. Kurisu S, Inoue I, Kawagoe T, Ishihara M, Shimatani Y, Mitsuba N, et al. Impact of the magnitude of the initial ST-segment elevation on left ventricular function in patients with anterior acute myocardial infarction. Circ J. 2004; 68:903-8.

18. Tao Zw, Huang Yw, Xia Q, Fu J, Zhao Zh, Lu $\mathrm{X}$, et al. Early association of electrocardiogram alteration with infarct size and cardiac function after myocardial infarction. Journal of Zhejiang University Science. 2004; 5(4):494-8.

19. Tiyantara MS, Furqon M, Paramita S. Pathological $Q$ wave as an indicator of left ventricular ejection fraction in acute myocardial infarction. Med J Indones. 2016; 25(2):98-103.

20. Siha H, Das D, Fu Y, Zheng Y, Westerhout CM, Storey RF, et al. Baseline $\mathrm{Q}$ waves as a prognostic modulator in patients with ST-segment elevation: insight from the PLATO trial. CMAJ. 2012; 184(10):1135-42.

21. Kaul P, Fu Y, Westerhout C, Granger C, Armstrong P. Relative prognostic value of baseline $Q$ wave and time from symptom onset among men and women with ST-elevation myocardial infarction undergoing percutaneous coronary intervention. Am J Cardiol. 2012; 110(11):1555-60.

22. Gale CP, Manda SOM, Weston CF, Birkhead JS, Batin PD, Hall AS. Evaluation of risk scores for risk stratification of acute coronary syndromes in the Myocardial Infarction National Audit Project (MINAP) database. Heart. 2009; 95(3):221-7.

23. Correia LCL, Garcia G, Kalil F, Ferreira F, Carvalhal M, Oliveira R, et al. Prognostic value of TIMI score versus GRACE score in ST-segment elevation myocardial infarction. Arq Bras Cardiol. 2014; 103(2):98-106.

24. Cullen L, Greenslade J, Hammett CJ, Brown AFT, Chew DP, Bilesky J, et al. Comparison of three risk stratification rules for predicting patients with acute coronary syndrome presenting to an Australian emergency department. Heart Lung Circ. 2013; 22(10):844-51. 